\title{
Институты развития социально-инвестиционной модели регионального управления в контексте обеспечения культурной безопасности Юга России
}

\author{
Воденко К.В., Дегтярев А.К. \\ Южно-Российский государственный политехнический университет (НПИ) \\ имени М.И. Платова, \\ Россия, 346428, Ростовская область, г. Новочеркасск, ул. Просвещения, д. 132 \\ E-mail: vodenkok@mail.ru, rse1985@mail.ru
}

\begin{abstract}
Аннотация. В рамках реализации поставленной цели рассмотрена проблема создания социальноинвестиционной модели развития региона как наиболее оптимальной для укрепления общероссийского пространства. Подчеркнуто, что в современной ситуации, когда российские регионы испытывают дефицит финансовых ресурсов, а ранее существовавшая политика финансовых трансферов подвергается ревизии со стороны Федерального Центра, актуализируется вопрос об обеспечении культурной безопасности регионов, особенно очевидный на Юге России как регионе, имеющем особенности в контексте геополитического положения, истории освоения и заселения, стереотипов этногруппового и социально-группового общения.
\end{abstract}

Ключевые слова: социально-инвестиционная модель, культурная безопасность, российские регионы, Федеральный центр, Юг России, внутрирегиональные отношения, стартовые условия.

Благодарности: исследование выполнено в рамках гранта Президента РФ для государственной поддержки молодых российских ученых - докторов наук (МД-1493.2020.6) на тему «Ресурс исторической памяти в системе институциональных параметров социально-инвестиционного развития и обеспечения культурной безопасности региона».

Для цитирования: Воденко К.В., Дегтярев А.К. 2021. Институты развития социальноинвестиционной модели регионального развития в контексте обеспечения культурной безопасности Юга России. Nomothetika: Философия. Социология. Право, 46 (2): 274-285. DOI 10.52575/2712746X-2021-46-2-274-285

\section{Institutions of development of a social and investment model of regional development in the context of ensuring the cultural security of the South of Russia}

\author{
Konstantin V. Vodenko, Alexander K. Degtyarev \\ Platov South-Russian State Polytechnic University (NPI), \\ 132 Prosveshcheniya St, Novocherkassk, Rostov Region, 346428, Russian Federation \\ E-mail: avvakumova_alina@mail.ru
}

\begin{abstract}
The study of the soil erosion process and its determining factors is of particular importance nowadays, in conditions of an increasing anthropogenic pressure. The article describes mathematical models of soil erosion and its development, created with the aim of a detailed analysis of the main soil erosion factors contribution (topography, soil types and particle size distribution) using large-scale soil and topographic maps. The main feature of the suggested models is that they are based on qualitative data (soil erosion categories determined by large-scale soil maps). The modeling areas of agricultural lands were
\end{abstract}


determined by remote sensing data. The analysis of the models coefficients allowed to single out the most common combination of conditions conducive to the development of soil erosion processes on agricultural land within the study area (The Republic of Tatarstan). The study in prospect gives an opportunity to contain zoning of the territory according to the probability of erosion processes development. It was found that the probability of soil erosion, as well as its intensification, increases with the following indicators: slope, specific catchment area, as well as a number of derived indices (convergence-divergence flow index, profile curvature and LS-factor).

Keywords: soil map, topography, soil type, Generalized Linear Model.

Acknowledgements: The article was prepared within the framework of grant by the President of the Russian Federation for state support of young Russian scientists - Doctors of Sciences (MD - 1493.2020.6) on the topic "The Resource of Historical Memory in the System of Institutional Parameters of SocialInvestment Development and Ensuring the Cultural Security of the Region".

For citation: Vodenko K. V., Degtyarev A. K. 2021. Institutions of development of a social and investment model of regional development in the context of ensuring the cultural security of the South of Russia. NOMOTHETIKA: Philosophy. Sociology. Law, 46 (2): 274-285 (in Russian). DOI 10.52575/2712-746X2021-46-2-274-285

\section{Введение}

Культурная безопасность как система мер государственной и общественной политики направлена на предотвращение и профилактику культурных девиаций, представляющих риск для нравственно-морального и социально-психологического самочувствия общества, становится актуальной, так как от состояния «духа» общества зависит не только свобода от катастрофических и предкатастрофических предчувствий и тревог, но и чувство социального оптимизма, уверенности в будущем, которое в условиях современной «поведенческой» экономики играет немаловажную роль в социально-политической ситуации в стране.

Учитывая, что Россия является страной регионов и основное население страны, несмотря на доминанты социально-миграционных потоков, сосредоточено в региональном пространстве, нельзя отрицать значимость вопроса культурной безопасности на региональном уровне, особенно на Юге России - регионе с геополитической и этнокультурной спецификой. Полагая, что культурная безопасность является составляющей социального портрета региона, также следует считать, что регион является привлекательным или непривлекательным с точки зрения инвестиционного критерия в силу фактора социального самочувствия и моделей поведения населения региона [Vodenko, 2019].

Логика развития регионов и межрегиональных отношений в российском обществе показала влияние двух факторов. Во-первых, инвестиционный вклад в региональное развитие основывается на принятии знаковости регионального пространства: культурного «бекграунда» региона, его образа в истории страны, уровня культурного общения населения. Можно сослаться на опыт зарубежных инвесторов, которые более охотно рассматривают инвестиционные проекты в регионах с культурной репутацией. И, напротив, если проблемные регионы с проточным населением, не обладающие культурным наследием, воспринимаются негативно, то не претендуют на роль культурных пространств. Во внутреннем аспекте выявляется значимость культурной безопасности в рамках возможностей реализации социально-инвестиционных проектов, связанных с образовательной, культурно-информационной сферами.

Во-вторых, культурная безопасность не является автономным фактором регионального развития, так как не может быть актуализирована вне состояния социально-инвестиционной модели региона. Другими словами, включение в действие человеческого капитала в ситуации, когда наращиваются культурные возможности и происходит сдвиг в сторону 
культурных акций, можно ожидать позитивный эффект от перспектив развития туризма или нацеливаться на укрепление регионального патриотизма. Реальный стимул культурной безопасности в росте социально-инвестиционной модели развития заключается, на наш взгляд, в следующем: культурная безопасность включена в критерии социальной инвестиционности, работает в контексте роста культурного разнообразия, толерантности в межличностных и межгрупповых отношениях и, следовательно, ориентирует региональное сообщество на то, что культурный образ населения регионов является позитивным для перспектив построения и реализации социально-инвестиционной модели развития [Воденко, 2020а, 2020б; Vodenko, 2020].

Таким образом, при рассмотрении вопроса культурной безопасности требуется понимание не только стратегии ее обеспечения со стороны федеральных и региональных властей, а также общественных институтов и организаций, но и отношение к социальным инвестициям в контексте сохранения культурного наследия и поиска в культурной сфере стимулов для инвестиционного развития. Очевидно, что одиночные проекты, которые предпринимались в предшествующие десятилетия («Пермь - культурная столица России»), несмотря на общественную полезность, не могут создать устойчивый вектор социально-инвестиционного развития региона, так как ожидаемо приводят к «пропогандистскому» эффекту и «быстро сдуваются», оставляя впечатление незавершенности и затратности. В этом смысле актуальными являются проработка вопросов методологии, выведение теоретических принципов и положений, направленных на анализ соотношений между социально-инвестиционной моделью развития в регионах и обеспечением культурной безопасности [Норт, 1997; Кушлин, 2011].

\section{Методология исследования}

Отечественная социологическая мысль направила исследовательские усилия на проблемы регионов и регионального развития относительно недавно, с конца 90-х годов $\mathrm{XX}$ века, когда на фоне восстановления территориальной целостности и конституционного порядка страны стало актуальным осмысление регионального пространства, динамики и статики региональных процессов, отношений регионов и Федерального центра. В рамках структурно-функционального подхода, задающего вектор рассмотрения организационноструктурных вопросов, социально-инвестиционная модель развития региона проглядывалась слабо. На это срабатывали причины, связанные с политикой «финансовых трансфертов», и речь шла о месте региона в сложившейся иерархии межрегиональных отношений, о том, что региональное развитие определяется ценробежными или центростремительными тенденциями, что инвестиционность региона основывается на перспективах экономического роста, ресурсном потенциале [Кравченко, 2015; Месхи, 2020; Региональная социология.., 2015].

В рамках социально-пространственного подхода, который можно считать шагом в анализе социально-инвестиционной модели развития, нашел отражение тот факт, что в результате действия распределительной политики Федерального центра, несмотря на внешний политико-стабилизационный эффект, выявляются риски чрезмерной зависимости от финансовой дотации Центра, вступают в действие неформальные механизмы отношений внутри властных структур, ощутимым становится коррупционный эффект и, как следствие, не формируется региональное пространство, реально разделенное по критерию социального клиентелизма. Поэтому реальный исследовательский акцент переносится на анализ региональной идентичности, «узлов» притяжения и дистанцирования в региональном пространстве различных групп регионального социума, и в таком смысле появляется необходимость определения социальной инвестиционности региона по критерию социального капитала групп регионального социума. Социально-пространственный подход определяет со- 
циально-инвестиционную модель региона через интеграционные/дезинтеграционные процессы (выявлено, что преобладание социальной дезинтеграции над интеграцией в районах Дальнего Востока делает их зонами социального риска для долгосрочных инвестиций). Но с социально-пространственным измерением региона связывается и возможность концентрации социальных инвестиций в регионах, обладающих близостью к Федеральному Центру и одновременно имеющим профессионально-квалификационный ресурс для регионального развития [Столицы и регионы.., 2018].

Юг России в рамках социально-пространственного подхода определяется проблемным в силу множественности социокультурных, этнокультурных, внутрирегиональных различий, создающих эффект «чересполосицы» и делающих сложным процесс внутрирегиональной социально-экономической интеграции. Здесь также срабатывает спорный административный вопрос, связанный с тем, что в региональное пространство включено Нижнее Поволжье (Волгоградская и Астраханская области), ориентированное исторически и экономически на другие регионы, поэтому для социально-пространственного подхода свойственно рассматривать возможности и ограничения по консолидации регионального пространства России.

В отличие от социально-пространственного подхода в рамках структурно-деятельностного измерения социально-инвестиционная модель развития региона предполагает проекцию отношений групп регионального социума на сформировавшееся региональное пространство как позиции и диспозиции социальных групп в качестве акторов регионального социума. В исследовательском контексте на первый план выходит анализ социальноинвестиционной модели в качестве ресурсоспособности акторов регионального социума наращивать конкурентоспособность и инновационность в качестве самостоятельных стимулов регионального развития. Однако возможны исследовательские сложности, определяемые тем, что не учитываются институционально-территориальные узлы, общесоциетальная и национально-государственная идентификации, и описание готовности к социально-инвестиционному развитию выглядит неполным, так как часто не принимается во внимание специфика социального поведения такой группы, как «бюджетники», зависимой от государственных дотаций и не имеющей значимого интереса к социально-инвестиционному развитию.

Тем не менее, структурно-деятельностный подход точно диагностирует такую особенность российской повседневности, как способность населения регионального социума к социально-адаптационным стратегиям, что достаточно убедительно выявилось в процессе исследования условий кризиса. Сопоставимость с показателями социальной адаптации населения в регионах дает возможность рассматривать социально-инвестиционную модель развития в зависимости от сроков перестройки социальной адаптации к социальным инвестициям, ориентированным на будущее и не содержащим краткосрочный полезный эффект. В этом смысле структурно-деятельностный подход интересен тем, что обращает внимание на культурную безопасность, так как анализирует социальную адаптацию с точки зрения «издержек», снижения толерантности в межличностных и групповых отношениях, перспективы актуализации культурно-исторического наследия в формировании ресурса исторической памяти, возможности создания соответствующей задачам регионального развития организационной инфраструктуры, основанной на обеспечении культурной безопасности [Пахомова, Дубровина, 2017; Тополева, 2019].

\section{Результаты исследования и их обсуждение}

Следует подчеркнуть, что культурная безопасность в соотношении с социально-инвестиционной моделью развития определяется как сопутствующая цель, условие нормального функционирования регионального социума и укрепления региональной идентичности 
как составной части национально-государственной идентичности. Данный фактор необходимо рассматривать обязательным, так как социальные инвестиции в России определяются целью консолидации регионов. Если ориентироваться на успех в этом направлении, следует принимать во внимание фактор укрепления межрегионального единства и движения к формированию нормально функционирующего межрегионального пространства [Воденко, Дегтярев, 2020].

Предыдущий опыт создания межрегиональных ассоциаций в 90-е годы XX века не получил позитивных импульсов, так как был связан с практиками межрегионального «бартера», с состоянием экономики при нарушении сложившихся хозяйственно-экономических связей и кризиса финансовой системы, когда действовал-принцип выживания, а не развития, что ставило на второй план социально-инвестиционный аспект. Культурная безопасность не являлась приоритетом в условиях принятия конъюктурных управленческих решений, а если выдвигалась в качестве повестки дня, то ее обсуждение определялось ориентированностью на общероссийский тренд поиска общенациональной идеологии. Следует подчеркнуть, что наступление периода обеспечения инвестиционного развития регионов сопряжено и с определением меры децентрализации государственного управления, и не в меньшей степени с вниманием к культурно-историческому контексту регионального развития, к тому, что культурная безопасность включает не только предупреждение социальных рисков, связанных с деструктивной исторической памятью и проблематичным состоянием культуры общения, а также и мобильностью регионального социума двигаться по пути социально-инвестиционного развития [Балакин, 2014; Божко, 2012].

Важный момент состоит в том, что социально-инвестиционное развитие подразумевает рост человеческого капитала, перестройку стратегии поведения населения региона в пользу «работы на будущее», больший вклад в образование. В этом смысле в российских регионах ощущается дефицит формирования референтной модели, так как регионы-доноры со спецификой «вахтовости» и «проточности» не готовы вкладывать ресурсы в долгосрочное социально-инвестиционное развитие, ориентированное на экономику с «добавленной стоимостью»; в то же время регионы-«середнячки» нацелены на социально-инвестиционное развитие как процедуру, предполагающую привлечение федеральных средств, и в таком контексте ожидание больших социально-инвестиционных проектов часто не оправдывается.

Региональные структуры регулярно заявляют о планах роста социальных инвестиций, но есть риск, что финансовые трансферы, поступающие из федерального бюджета, используются не по назначению, поскольку находятся поводы для их направления на поддержание социальной инфраструктуры, ликвидацию узких мест политики, социальную помощь, на исправление кризисной ситуации в здравоохранении, даже на расчет по накопившимся долгам в региональном бюджете. Учитывая это обстоятельство, Федеральный Центр вносит коррективы, определяемые осторожностью подхода политики финансовых трансферов. Какое это отношение имеет к культурной безопасности? На наш взгляд, проявляется взаимное недоверие не столько в вопросах определения целей социально-инвестиционного развития, где Федеральный Центр заинтересован в снятии чрезмерной финансовой нагрузки, сколько в том, что в регионах не исчезает, а часто укрепляется процесс «внутренней колонизации», выкачивания ресурсов из регионов при неполном возмещении и компенсации со стороны Федерального Центра.

Риски культурной безопасности возрастают в контексте оживления «антимосковских» настроений, подпитываемых синдромом «замкадья», пущенном в оборот в московских либеральных СМИ, и имеющих последствия в непонимании специфики социальноинвестиционного развития региона как взаимовыгодного с точки зрения прекращения депопуляции закрепления молодых кадров и импульса для развития «вторичного» и «третичного» секторов, содержащих возможность для реального роста человеческого капитала и 
востребованности на уровне стратегии населения регионов. В этом смысле становится очевидным, что в перспективе модель социально-инвестиционного развития переводится в сферу культурной безопасности, формирование на уровне массовых настроений, ценностей гражданственности и профессионализма, толерантности к социально-бытовым и этнокультурным различиям и нетерпимости к криминализации и теневизации общественной и экономической жизни.

Логика формирования и развития социально-инвестиционной модели в региональном пространстве исходит из того, что в российских условиях необходима ориентация на баланс централизации и децентрализации, что культурная безопасность основывается на паритете и совместимости общенациональной и региональной идентичности, что формирование чувства малой родины предполагает признание позиции «Россия - наш общий дом», и не вызывающим возражения является фактор региональной открытости, свободного перемещения россиян, возможности трудоустройства и обживания в новом регионе.

Разумеется, российские регионы не одинаковы, они различаются по природно-климатическим и социально-экономическим условиям. Объективной является тенденция переезда из регионов со сложностями повседневной жизни в региональные образования, имеющие позитивный образ адаптации и решения жизненных проблем. Естественно, федеральные власти заинтересованы в целях национальной безопасности в оптимальном распределении демографических ресурсов на территории России в том, чтобы регионы не попадали в «демографическую ловушку», и на это нацелена запущенная недавно Федеральная программа по развитию Дальнего Востока. Пока получены очень скромные результаты, и ясно - стимул в виде «дальневосточного гектара» не является действенным, если учесть, что большинство потенциальных мигрантов настроены на проживание в локальностях с развитой социальной инфраструктурой, и в современных условиях было бы нелепо ссылаться на опыт заселения Сибири и Дальнего Востока в период столыпинских реформ, очевидного несоответствия состава переселенцев и векторов устойчивого социально-инвестиционного развития.

В современной ситуации реальным в достижении поставленных целей можно предполагать стимулирование внутренней миграции на уровне принятия согласованной с регионами политики по привлечению перспективных кадров в рамках решения внутрирегиональных и межрегиональных социально-экономических проблем. Это означает переход к содержательной модели культурной безопасности, основанной на знании и понимании культуры региона: регионы с «проточной» культурой нацелены на временное проживание, различаются от регионов с традицией оседлости. Также необходимо принимать во внимание и исторические факты заселения регионов, когда криминальная субкультура в Забайкалье имеет крепкие основания по сравнению с влиянием рисков «анархии» и безразличия в Хакасии или Бурятии.

В этом направлении необходимо продолжение политики укрепления регионов. Несмотря на определенные административные и социально-психологические издержки, функционирование новых региональных образований, таких как Камчатский край, Пермский край, Забайкальский край, дает повод для сдержанного оптимизма, поскольку свидетельствует о постепенном исчезновении рисков социально-территориальной изоляции, укрепления внутрирегиональной мобильности, целенаправленного использования финансовых ресурсов для реализации социально-инвестиционных проектов. Необходимо добиться понимания того, что отмеченный процесс не является только уделом амбиций региональных элит, но и связан с перспективами социально-инвестиционного развития [Осипов, 2007].

В силу территориальных масштабов, множественности социальных проблем в региональном пространстве России при их доминантной однотипности политика укрупнения вли- 
яет и на скорость решения актуальных проблем регионального развития и способствует закреплению стратегии культурной безопасности как представляющей реальный практический интерес. Действительно, одно дело - производить часто малорезультативный мониторинг настроений в региональном социуме, связанных с синдромами «заброшенности» и «самоизоляции», другое - предотвращать риски, определяемые региональными диспропорциями.

В этом отношении вступает в действие вектор социально-инвестиционного развития, формирование условий для роста социального оптимизма, понимания того, что кризис в стране связан в основном с внутренними факторами, с тем, что в обществе настроения «жизнь будет хуже» определяют сужение возможностей социально-инвестиционного развития. Есть расхожее мнение, что причиной большинства «бед» в российских регионах является то, что население так и не научилось работать в условиях рынка. Однако по этому поводу можно привести основательные возражения, связанные с тем, что в России так и не сложился нормативный рыночный порядок, что большинство российских регионов прошли период деиндустриализации, но так и не вступили в эпоху экономики знания, что в качестве одной из главных причин можно назвать отсутствие последовательной региональной политики.

Одной из важных сторон современной жизни российских регионов является формирование социальных и культурных предпочтений, ориентированных на «приватизацию» социальной жизни, «низведению высших ценностей на бренную землю». Иными словами, перевод целей социально-инвестиционного развития в логику повседневности, осознание взаимосвязи между региональными проектами и повышением качества жизни населения социума, предпринимаемые со стороны Федерального Центра и региональных властей действия, направленные на изменения в региональном пространстве, не инициировали волну социального энтузиазма, поскольку влияют на жизнь социально активного меньшинства, представителей экономических и общественных ассоциаций, бизнес-сообщества, интеллектуальных элит. Признавая, что эти слои определяют доминанту морально-психологического климата в регионе, нельзя абсолютизировать их влияние на состояние культурной безопасности.

Дело в том, что уровень и качество культурной безопасности определяются культурными стереотипами, формируемыми в массовых настроениях населения регионального социума. Если взять, например, Юг России, то можно сказать, что здесь проявляются стереотипы «пограничности», смежности с этнокультурными влияниями Большого Кавказа. Вероятно, на становление культурных стереотипов и отношение к культурной безопасности как сохранению и воспроизводству культурных ценностей в регионе влияют культурно-исторические факторы. На Юге России, учитывая процесс внутренней миграции, освоение региона русскими переселенцами, последствия кавказских войн, можно говорить о том, что чувство культурной безопасности часто перевешивает социально-инвестиционный фактор. Внутри регионального пространства, где локализуются исторические обиды и тревоги по поводу сохранения культурного наследия, социальные инвестиции могут рассматриваться на уровне массового сознания и массовых настроений как фактор с многими неизвестными, содержащими риски для культурной безопасности в контексте утраты традиций, обычаев, исторической памяти и в целом культурной ассимиляции [Историческая память.., 2020].

В этом контексте можно говорить, что социально-инвестиционная модель, если ее принимать как не декларируемую, а направленную на рост ресурсного потенциала региона, воспринимается на уровне готовности элит и масс региона действовать, исходя из согласования интересов и позиций большинства населения. Здесь важную роль играет социальнопсихологическая подготовка, осуществляемая властными и общественными институтами для формирования целей и способов социально-инвестиционного развития как содержащих потенциальное приобретение для большинства населения регионального социума. Непол- 
ный эффект от реализации социально-инвестиционной модели ожидаем в условиях игнорирования уровня культурной безопасности, отношения к массовым культурным стереотипам как анахронизмам и рецидивам массового сознания старших поколений. Акцент на роль молодежи как субъекта социальных и культурных инноваций может быть заблуждением, так как следует учитывать социальную неоднородность молодежной среды, тренды демонстративной идентичности, настроения провинциализма или оторванности от региональной жизни.

Суммируя эти факторы, можно говорить о том, что культурная безопасность является разнонаправленным вектором: с одной стороны, при состоянии, характеризуемом как направленное на устойчивое региональное развитие, доминирует ориентир на будущее региона, актуализацию культурной безопасности в рамках социально-инвестиционной политики; с другой - очевидным является фактор риска, связанный с возможностями социальной и культурной изоляции групп и слоев, воспринимающих цели социально-инвестиционного развития как роста человеческого капитала, ведущий к маргинализации, утраты ими социально-статусных позиций (дохода и престижа). Это особенно касается сельского населения, поскольку в нынешних условиях традиционный труд перестал восприниматься в качестве позитивного фактора и в рамках модернизации сельскохозяйственного производства наблюдается старение и отток кадров, утрата навыков и способов ведения домашнего хозяйства и солидарности на социально-бытовом уровне.

Характерно, что особенностью понимания социально-инвестиционной модели в региональном пространстве является дискурс «постиндустриального общества», которое складывается в зарубежном пространстве, но в России является в основном «социальной химерой», существует в большей степени в воображении столичных интеллектуальных элит, чем в реальности российских регионов. В условиях необходимости перехода от адаптации к развитию социально-инвестиционная модель определяется оценкой объективных и субъективных шансов роста человеческого капитала исходя из сложившихся исторически хозяйственно-экономических и социокультурных связей. Поэтому значимость социальноинвестиционной модели для российских регионов определяется тем, чтобы не стать «несостоявшимися» по аналогу с некоторыми государствами, безнадежно отставшими в перспективах социального и политического развития, и самое главное - в рамках сохранения единого межрегионального пространства получить больше возможностей для внутрирегионального и межрегионального развития.

Как правило, в отношениях между Федеральным Центром и российскими регионами определяющими являются политические, административно-правовые и финансовые регуляторы, которые полезны в целях поддержания целостности большой страны, но при этом проявляется ограниченность наработанных схем отношений, что на наш взгляд, связано с тем, что и в Федеральном Центре сдержанно относятся к социально-инвестиционному развитию региона как росту политических амбиций региональных элит, и в региональном пространстве просматривается тенденция разделения на «центр» и «периферию», концентрацию усилий на развитие избранных «локальностей» и отношения по «остаточному принципу» с другими сегментами регионального пространства.

Не ушедшей в прошлое остается «война» по поводу перераспределения ресурсов, когда причиной является неравенство природных, социальных и демографических условий (Вологда и Череповец, Псков и Великие Луки, Красноярск и Норильск). Между тем, признавая необходимость нормализации внутрирегиональных отношений, следует задуматься о принятии социально-инвестиционной модели развития, ориентированной на становление актуального партнерства, на реализацию проектов, благодаря которым могут быть и решены накопившиеся проблемы региона, и дана возможность развития зонам социальной и 
экономической депрессии. В наиболее проблемном регионе Юга России, таком как Калмыкия, очевидной представляется стратегия возрождения сельского хозяйства с опорой на переработку и развитие логистики, связанной с близостью транскаспийских маршрутов [Public Administration.., 2020].

Фактор культурной безопасности является актуальным, поскольку есть необходимость преодоления посттравматического состояния населения и освоение новых технологий и интеллектуальных продуктов в рамках межрегиональной взаимопомощи, направлении в Калмыкию специалистов и экспертов, способных помочь республике в сдвиге с мертвой точки. При этом не следует увлекаться опытом прошлого, пытаться реализовать проекты, связанные с бесперспективной затратой финансовых ресурсов и экологическими рисками (стратегия расширения поливного земледелия). Подобная схема противоречит и поддержанию культурной безопасности, потому что предсказуемо приведет к этнокультурному конфликту, сопротивлению по поводу новой версии советской коллективизации, так как в массовых настроениях местного социума укоренены традиции кочевничества, расходящиеся с культурой земледельческой оседлости.

В том же контексте можно говорить и о стремлении развивать социально-инвестиционную модель в региональном пространстве, игнорируя культурные особенности таких регионов, как Горный Алтай, Хакасия, Якутия, Мари Эл. Объединяющим негативным фактором можно считать оценку культурной безопасности в качестве нулевой составляющей, то есть не влияющей на стартовые условия и возможности социально-инвестиционного развития. Однако, как мы подчеркивали выше, стратегии обеспечения социально-инвестиционного развития региона опираются на культурную безопасность, имеющую степень привлекательности или непривлекательности и для внешних инвесторов, для создания позитивного имиджа региона в отношении с Федеральным Центром и для внутрирегионального развития, где существует запрос на региональный патриотизм властных и интеллектуальных элит, на сильную региональную идентичность, которая включает принятие сложившегося культурно-исторического опыта в целях определения совокупности способов роста человеческого капитала [Павлов, 2009; Курдюков, 2013; Матюнин, 2015].

\section{Заключение}

Российские исследователи укрепились в мысли, что в практической региональной политике в стране является необходимым учет соотношения ресурсности и социальной обустроенности территорий, и в этом смысле социально-инвестиционная модель развития региона направлена на удовлетворение запроса на межрегиональную стабильность как условие сохранения и укрепления территориальной целостности России.

Выявленные связи и различия в культурной безопасности показывают, что стартовая площадка социально-инвестиционного развития региона основывается на признании и учете рисков и преимуществ, накопленных в процессе культурно-исторического развития, который имеет, безусловно, особенности в зависимости от истории освоения и заселения региона, социально-демографического и этнокультурного состава, социально-бытовых и социально-хозяйственных стереотипов, «проточного» или оседлого образа жизни, уровня региональной идентичности. Таким образом, в социально-инвестиционной модели развития могут реализоваться или не реализоваться сценарии умножения неопределенности, связанные с будущим региона, или наблюдаться процесс интеграции региона в общероссийское пространство по критерию ухода из зоны отставания на среднероссийский уровень.

Говорить о том, что социально-инвестиционная модель развития ставит амбициозные цели «выбивания в лидерство», является некорректным, так как действующая в России ресурсная модель экономики воспроизводит различия в межрегиональном пространстве в основных социально-статусных показателях (доходы населения) и в качестве негативного по- 
следствия сужает возможности несырьевых регионов в реализации модели социально-инвестиционного развития, так как стимулирует отток молодых и энергичных кадров, сужая возможности на местах реализовать полезные и достижимые инвестиционные проекты. Но главный вывод состоит в том, что, несмотря на коллизии прошлого и актуальность действующей распределительной системы между регионами, воспроизводящей клиентелистскую зависимость, на уровне властных и интеллектуальных региональных элит очевиден запрос на социальные инвестиции как способ решения ключевых региональных проблем.

\section{Список литературы}

1. Балакина Г.Ф. 2014. Инструменты регулирования социально-экономического развития регионов. Региональная экономика: теория и практика, 39 (336): 2-12.

2. Божко Ю.Н. 2012. Современные подходы к управлению региональным развитием. Социально-экономические явления и процессы, 9 (43): 18-22.

3. Воденко К.В. 2020. Система высшего образования и социально-инвестиционная модель регионального развития в контексте обеспечения безопасности Юга России. Alma Mater (Вестник высшей школы), 11: 12-19.

4. Воденко К.В. 2020. Теория и методология исследования роли ресурса исторической памяти в формировании социально-инвестиционной модели регионального развития. Гуманитарий Юга России, 2: 258-267.

5. Воденко К.В., Дегтярев А.К. 2020. Роль исторической памяти в развитии социальноинвестиционной модели регионального управления. Социальные трансформации в контексте пространственного развития России: Материалы Второго Крымского социологического форума. Ростов-на-Дону, Издательство Фонд науки и образования, 647-654.

6. Историческая память в социальных процессах поликультурного региона: институциональная специфика регионального развития и потенциал в обеспечении культурной безопасности общества. 2020. Под ред. К.В. Воденко. Ростов-на-Дону: Фонд науки и образования, $134 \mathrm{c}$.

7. Кравченко С.А. 2015. Социологическое знание через призму стрелы времени: востребованность гуманистического поворота. М., МГИМО-Университет, 342 с.

8. Курдюков С.И. 2013. Региональные инвестиционные проекты. Управление экономическими системами. 12 (60) [Электронный pecypc]. https:/elibrary.ru /contents.asp?id=33955486 (дата обращения: 10.03.2020). 11: $65-74$.

9. Кушлин В. 2011. Институциональная среда инновационной модернизации. Экономист,

10. Матюнин Л.В. 2015. Инвестиционные проекты: содержание, структура. Вестник Университета. 9: 89-91.

11. Месхи Б.Б. 2020. Региональное управление в фокусе социологической мысли. Гуманитарий Юга России, 1: 280-290.

12. Норт Д. 1997. Институциональные изменения: рамки анализа. Вопросы экономики, 3 : $6-17$.

13. Осипов А.К. 2007. Система регионального управления: понятие, функции и правовое обеспечение. Вестник Удмуртского университета, 6: 11-18.

14. Павлов А.Ю. 2009. Управление современными инвестиционными и социальноориентированными инвестиционными проектами и их классификация. Известия ЮФУ. Технические науки. 3 (92): 110-115.

15. Пахомова О.А., Дубровина О.А. 2017. Системный подход к управлению социальной сферой региона. Экономика и предпринимательство, 8-1(85): 352-356.

16. Региональная социология: проблемы консолидации социального пространства России. 2015. Под ред. В. В. Маркина. М., Новый хронограф, 621 с.

17. Столицы и регионы в современной России. Мифы и реальность пятнадцать лет спустя. 2018. Под ред. М.К. Горшков. М., Весь Мир, 312 с.

18. Тополева Т.Н. 2019. Региональное развитие: новые теории. Economics Juvenis scientia, 6: $14-17$. 
19. Konstantin V. Vodenko. 2019. Problems and Perspectives of State Regulation of System of Education in the Context of Provision of Russia's National Security. International Journal of educational management, 33(3): 462-469.

20. Public Administration and Regional Management in Russia - Challenges and Prospects in a Multicultural Region. 2020. E.G. Popkova and K.V. Vodenko (eds.). Cham: Springer International Publishing AG, $567 \mathrm{p}$.

\section{References}

1. Balakina G.F. 2014. Instrumenty regulirovaniya social'no-ekonomicheskogo razvitiya regionov [Tools for regulating the socio-economic development of regions. Regional economy: theory and practice]. Regional'naya ekonomika: teoriya i praktika, 39 (336): 2-12.

2. Bozhko Y.N. 2012. Sovremennye podhody k upravleniyu regional'nym razvitiem [Modern approaches to regional development management]. Social'no-ekonomicheskie yavleniya i process, 9 (43): $18-22$.

3. Vodenko K.V. 2020. Sistema vysshego obrazovaniya i social'no-investicionnaya model' regional'nogo razvitiya $\mathrm{v}$ kontekste obespecheniya bezopasnosti Uga Rossii [The system of higher education and the socio-investment model of regional development in the context of ensuring the security of the South of Russia]. Alma Mater (Vestnik vysshej shkoly), 11: 12-19.

4. Vodenko K.V. 2020. Teoriya i metodologiya issledovaniya roli resursa istoricheskoj pamyati v formirovanii social'no-investicionnoj modeli regional'nogo razvitiya [Theory and methodology of research on the role of the historical memory resource in the formation of the social and investment model of regional development]. Gumanitarij Uga Rossii, 2: 258-267.

5. Vodenko K.V., Degtyarev A.K. 2020. Rol' istoricheskoj pamyati v razvitii social'noinvesticionnoj modeli regional'nogo upravleniya [The role of historical memory in the development of the social and investment model of regional governance]. Social'nye transformacii $\mathrm{v}$ kontekste prostranstvennogo razvitiya Rossii: Materialy Vtorogo Krymskogo sociologicheskogo foruma. RostovnaDonu: Izdatel'stvo Fond nauki i obrazovaniya: 647-654.

6. Istoricheskaya pamyat' v social'nyh processah polikul'turnogo regiona: institucional'naya specifika regional'nogo razvitiya i potencial $\mathrm{v}$ obespechenii kul'turnoj bezopasnosti obshchestva [Historical memory in the social processes of a multicultural region: the institutional specifics of regional development and the potential for ensuring the cultural security of society]. 2020. Ed. K.V. Vodenko. Rostov-na-Donu: Fond nauki i obrazovaniya, $134 \mathrm{p}$.

7. Kravchenko S.A. 2015. Sociologicheskoe znanie cherez prizmu strely vremeni: vostrebovannost' gumanisticheskogo povorota [Sociological knowledge through the prism of the arrow of time: the demand for a humanistic turn]. M., MGIMO-Universitet, $342 \mathrm{p}$.

8. Kurdyukov S.I. 2013. Regional'nye investicionnye proekty. Upravlenie ekonomicheskimi sistemami [Regional investment projects. Management of economic systems]. 12 (60) [Elektronnyj resurs]. https://elibrary.ru/contents.asp?id=33955486 (data obrashcheniya: 10.03.2020).

9. Kushlin V. 2011. Institucional'naya sreda innovacionnoj modernizacii [The institutional environment of innovative modernization]. Ekonomist, 11: 65-74.

10. Matyunin L.V. 2015. Investicionnye proekty: soderzhanie, struktura [Investment projects: content, structure]. Vestnik Universiteta, 9: 89-91.

11. Meskhi B.B. 2020. Regional'noe upravlenie v fokuse sociologicheskoj mysli [Regional management in the focus of sociological thought]. Gumanitarij Yuga Rossii, 1: 280-290.

12. Nort D. 1997. Institucional'nye izmeneniya: ramki analiza [Institutional change: a framework for analysis]. Voprosy ekonomiki, 3: 6-17.

13. Osipov A.K. 2007. Sistema regional'nogo upravleniya: ponyatie, funkcii i pravovoe obespechenie [The system of regional management: concept, functions, and legal support]. Vestnik Udmurtskogo universiteta, 6: 11-18.

14. Pavlov A.Y. 2009. Upravlenie sovremennymi investicionnymi i social'no-orientirovannymi investicionnymi proektami i ih klassifikaciya [Management of modern investment and socially-oriented investment projects and their classification]. Izvestiya YUFU. Tekhnicheskie nauki, 3 (92): 110-115.

15. Pahomova O.A., Dubrovina O.A. 2017. Sistemnyj podhod k upravleniyu social'noj sferoj regiona [A systematic approach to the management of the social sphere of the region]. Ekonomika $\mathrm{i}$ predprinimatel'stvo, 8-1(85): 352-356. 
16. Regional'naya sociologiya: problemy konsolidacii social'nogo prostranstva Rossii [Regional sociology: problems of consolidation of the social space of Russia]. 2015. Ed. V.V. Markina. M., Novyj hronograf, $621 \mathrm{p}$.

17. Stolicy i regiony v sovremennoj Rossii. Mify i real'nost' pyatnadcat' let spustya [The capital and the regions in modern Russia. Myths and reality fifteen years later]. 2018. Pod red. M.K. Gorshkova. M., Ves' Mir, 312 p.

18. Topoleva T.N. 2019. Regional'noe razvitie: novye teorii [Regional development: new theories]. Economics Juvenis scientia. 6: 14-17.

19. Konstantin V. Vodenko. 2019. Problems and Perspectives of State Regulation of System of Education in the Context of Provision of Russia's National Security. International Journal of educational management, 33(3): 462-469.

20. Public Administration and Regional Management in Russia - Challenges and Prospects in a Multicultural Region. 2020. E.G. Popkova and K.V. Vodenko (eds.). Cham: Springer International Publishing AG, $567 \mathrm{p}$.

\section{СВЕДЕНИЯ ОБ АВТОРАХ}

Дегтярев Александр Константинович, доктор философских наук, профессор кафедры юриспруденции Южно-Российского государственного политехнического университета (НПИ) имени М.И. Платова, Новочеркасск, Россия

Воденко Константин Викторович, доктор философских наук, профессор кафедры социальных и гуманитарных наук Южно-Российского государственного политехнического университета (НПИ) имени М.И. Платова, Новочеркасск, Россия

\section{INFORMATION ABOUT THE AUTHORS}

Alexander K. Degtyarev, Doctor of Philosophy, Professor, Professor, Department of Jurisprudence Platov South-Russian State Polytechnic University (NPI), Novocherkassk, Russia

Konstantin V. Vodenko, Doctor of Philosophy, Professor, Department of Social Sciences and Humanities, M.I. Platov South Russian State Polytechnic University (NPI), Novocherkassk, Russia 